\title{
Phototoxicity Evaluation of Pharmaceutical Substances with a Reactive Oxygen Species Assay Using Ultraviolet A
}

\author{
Yong Sun Lee ${ }^{1 \dagger}$, Jung-Sun $\mathrm{Yi}^{1 \dagger}$, Hye Rim Lim², Tae Sung Kim ${ }^{1}$, Il Young Ahn', Kyungyuk Ko', \\ JooHwan Kim ${ }^{1}$, Hye-Kyung Park ${ }^{3}$, Soo Jung Sohn ${ }^{4}$ and Jong Kwon Lee ${ }^{1}$ \\ ${ }^{1}$ Toxicological Screening and Testing Division, ${ }^{2}$ Herbal Medicinal Products Division, ${ }^{3}$ Toxicological Evaluation and Research Department, \\ ${ }^{4}$ Toxicological Research Division, National Institute of Food and Drug Safety Evaluation, Ministry of Food and Drug Safety, \\ Cheongju, Korea
}

(Received November 10, 2016; Revised November 28, 2016; Accepted December 2, 2016)

\begin{abstract}
With ultraviolet and visible light exposure, some pharmaceutical substances applied systemically or topically may cause phototoxic skin irritation. The major factor in phototoxicity is the generation of reactive oxygen species (ROS) such as singlet oxygen and superoxide anion that cause oxidative damage to DNA, lipids and proteins. Thus, measuring the generation of ROS can predict the phototoxic potential of a given substance indirectly. For this reason, a standard ROS assay (ROS assay) was developed and validated and provides an alternative method for phototoxicity evaluation. However, negative substances are over-predicted by the assay. Except for ultraviolet A (UVA), other UV ranges are not a major factor in causing phototoxicity and may lead to incorrect labeling of some non-phototoxic substances as being phototoxic in the ROS assay when using a solar simulator. A UVA stimulator is also widely used to evaluate phototoxicity in various test substances. Consequently, we identified the applicability of a UVA simulator to the ROS assay for photoreactivity. In this study, we tested 60 pharmaceutical substances including 50 phototoxins and 10 non-phototoxins to predict their phototoxic potential via the ROS assay with a UVA simulator. Following the ROS protocol, all test substances were dissolved in dimethyl sulfoxide or sodium phosphate buffer. The final concentration of the test solutions in the reaction mixture was 20 to $200 \mu \mathrm{M}$. The exposure was with $2.0 \sim 2.2 \mathrm{~mW} / \mathrm{cm}^{2}$ irradiance and optimization for a relevant dose of UVA was performed. The generation of ROS was compared before and after UVA exposure and was measured by a microplate spectrophotometer. Sensitivity and specificity values were $85.7 \%$ and $100.0 \%$ respectively, and the accuracy was $88.1 \%$. From this analysis, the ROS assay with a UVA simulator is suitable for testing the photoreactivity and estimating the phototoxic potential of various test pharmaceutical substances.
\end{abstract}

Key words: Alternative testing method, Photosafety screening, Phototoxicity, Photoreactivity, Reactive oxygen species, Ultraviolet A

\section{INTRODUCTION}

Phototoxicity is an acute light-induced skin irritation when

Correspondence to: Soo Jung Sohn, Toxicological Research Division, National Institute of Food and Drug Safety Evaluation, Ministry of Food and Drug Safety, Cheongju 28159, Korea

E-mail: sjsohn@korea.kr

Jong Kwon Lee, Toxicological Screening and Testing Division, National Institute of Food and Drug Safety Evaluation, Ministry of Food and Drug Safety, Cheongju 28159, Korea

E-mail: jkleest@korea.kr

${ }^{\dagger}$ These authors contributed equally to this study.

This is an Open-Access article distributed under the terms of the Creative Commons Attribution Non-Commercial License (http:// creativecommons.org/licenses/by-nc/3.0) which permits unrestricted non-commercial use, distribution, and reproduction in any medium, provided the original work is properly cited. photoreactive chemicals are topically or systemically applied (1). Phototoxicity begins when photoreactive chemicals are excited by absorption of ultraviolet and visible light (UV/ VIS). The excited chemicals can then transfer the absorbed energy and generate reactive oxygen species (ROS). The increased ROS levels provoke cytotoxicity through damage of DNA, lipids and proteins by oxidative stress $(2,3)$. Several types of drugs, such as antibiotics, anticonvulsants, antimalarials, antipsychotics, thiazide diuretics, non-steroidal anti-inflammatory drugs and others, have phototoxic potential and can cause notable phototoxic reactions such as sunburn and hyperpigmentation (4-6). Because of druginduced phototoxicity, regulatory agencies, US FDA, EU EMA and ICH, provide photosafety guidances, introducing test methods and evaluation strategies $(1,7,8)$. Following the ICH guidance S10, few non-animal testing methods for phototoxicity are recommended and these include measure- 
ment of the molar extinction coefficient (MEC), a standard ROS assay, a 3T3 neutral red uptake phototoxicity assay and a reconstructed human skin model assay.

The ROS assay was developed to screen photoreactivity of drugs through generation of the superoxide anion (type 1 reaction) and singlet oxygen (type 2 reaction) and their generation is an early stage chemical reaction as part of the phototoxicity mechanism (6). The ROS assay protocol was established and the validation studies were conducted under the direction of the Japanese Center for the Validation of Alternative Methods (JaCVAM) (9-11). For the assay, high sensitivity and reproducibility were demonstrated and as part of the test, two solar simulators Suntest CPS series and SXL-2500V2 were evaluated. This assay, however, has low specificity, showing high false positive results. For this reason, we only focused on the effect of UVA (315 400 nm), which is much important than other ultraviolet in phototoxicity. In addition, a UVA simulator is commonly used for phototoxicity evaluations. In this study, we evaluated the performance of the ROS assay with UVA (UVA ROS assay) instead of sunlight (290 700 nm) using 50 phototoxins and 10 non-phototoxins.

\section{MATERIALS AND METHODS}

Chemicals and materials. Sixty test substances, including reference chemicals and phototoxic/non-phototoxic drugs, were selected for evaluation from the ROS assay protocol, a validation report of the ROS assay, package inserts and previous studies (6,9-16). 4-Aminobenzoic acid, 6-methylcoumarin, 8-methoxy psoralen, acridine, amiodarone, amlodipine, amoxapine, aspirin, atorvastatin, benzocaine, bezafibrate, bithionol, chlorothiazide, chlorpromazine $\mathrm{HCl}$, ciprofloxacin, dapsone, demeclocycline, diclofenac, doxycycline, erythromycin, fenofibrate, flutamide, fluvastatin, furosemide, gliclazide, griseofulvin, hydrochlorothiazide, ibuprofen, ketoprofen, levofloxacin, losartan, lovastatin, methotrexate, nalidixic acid, naproxen, nifedipine, nitrofurantoin, norfloxacin, octyl salicylate, ofloxacin, omeprazole, oxytetracycline $\mathrm{HCl}$, penicillin $\mathrm{G}$, perphenazine, phenytoin, piroxicam, promethazine $\mathrm{HCl}$, quinidine, quinine $\mathrm{HCl}$, tetracycline, tiaprofenic acid, dimethyl sulfoxide (DMSO), sodium phosphate monobasic, sodium phosphate dibasic, p-nitroso-dimethylaniline (RNO), imidazole and nitroblue tetrazolium chloride (NBT) were purchased from Sigma-Aldrich (St. Louis, MO, USA). Enoxacin, lomefloxacin, meloxicam, mequitazine, nitrendipine, pitavastatin and rosiglitazone were obtained from Santa Cruz (Dallas, TX, USA). L-Histidine and sulisobenzone were purchased from Tokyo Chemical Industry (Tokyo, Japan). Quartz reaction containers were obtained from Ozawa Science (Aichi, Japan). Spectrophotometer cuvettes were purchased from Eppendorf (Hamburg, Germany). The 96-well plates (clear, flat-bottom, without lid) were obtained Corning (Corning, NY, USA). Following the ROS assay protocol, $20 \mathrm{mM}$ sodium phosphate buffer (NaPB, pH 7.4), $0.2 \mathrm{mM}$ p-Nitrosodimethylaniline (RNO), $20 \mathrm{mM}$ imidazole and $0.4 \mathrm{mM}$ nitroblue tetrazolium chloride (NBT) were prepared (10). All test substances and reagents were protected from light.

UV spectral analysis. UV spectral analysis was conducted as described in a previous study (6). The test substances were dissolved in $20 \mathrm{mM}$ sodium phosphate buffer (NaPB, pH 7.4) at $20 \mu \mathrm{M}$ (final concentration). The UV/ VIS absorption spectra were analyzed with a microplate spectrophotometer (Mecasys, Daejeon, Korea), and a spectrophotometer cuvette with a $10-\mathrm{mm}$ pathlength was used. The MEC values were calculated using the highest absorption peaks from 290 to $700 \mathrm{~nm}$.

Conditions of irradiation. A UVA simulator equipped with $40 \mathrm{~W}$ lamps was used (Vilbert-Lourmat, Marne-la-vallee, France). The UVA irradiation test was conducted at $25^{\circ} \mathrm{C}$ with $2.0 \mathrm{~mW} / \mathrm{cm}^{2}$ irradiance measured by a UVA detector (UVP, Cambridge, UK).

Reactive oxygen species (ROS) assay. ROS assay was performed as previously described in Onoue et al. $(9,11)$ and the ROS assay protocol (10). Stock solutions of all test substances were prepared at $10 \mathrm{mM}$ in DMSO or $20 \mathrm{mM}$ sodium phosphate buffer (NaPB, pH 7.4) and used within the same day for accurate data. To detect the generation of singlet oxygen and superoxide anion, all prepared test substance stock solutions were mixed in reagents, containing $400 \mu \mathrm{M}$ NBT in $20 \mathrm{mM} \mathrm{NaPB}$ (pH 7.4) for singlet oxygen (SO) and $200 \mu \mathrm{M}$ RNO and $50 \mu \mathrm{M}$ imidazole in $20 \mathrm{mM}$ $\mathrm{NaPB}(\mathrm{pH}$ 7.4) for superoxide anion (SA) detection, and the final concentration of test substances in the reaction mixture was at $200 \mu \mathrm{M}$. When precipitation was observed using a microscope $(\times 100$ magnification $)$ in the reaction mixture, appropriate final concentrations $(20,50,100 \mu \mathrm{M})$ were used. Two hundred microliters of each reaction mixture were put into three wells of a 96-well plate. Before UVA exposure, absorbance was measured at $440 \mathrm{~nm}$ for $\mathrm{SO}$ and $560 \mathrm{~nm}$ for SA by a microplate spectrophotometer and then a quartz reaction container was installed in the plate. The plate was irradiated with a UVA simulator. After irradiation, the absorbance at $440 \mathrm{~nm}$ and $560 \mathrm{~nm}$ for the plate was measured. Following the ROS assay protocol, ROS generation of SO and SA was calculated by mean absorbance before and after irradiation.

Data judgment. Photoreactivity of the test substances was judged according to the following criteria $(10,11)$. A test substance was classified as a photoreactive substance when an SO value 25 or more and/or an SA value 20 or more was measured; in turn, it was judged to be a non-photoreactive substance when values of less than 25 for $\mathrm{SO}$ and 
less than 20 for SA were recorded.

\section{RESULTS}

Optimization of the irradiance dose. To use a UVA simulator, we performed a preliminary study in order to find the appropriate UVA dose with the reference chemicals listed in the ROS assay protocol (10). We exposed at 2.0 $\mathrm{mW} / \mathrm{cm}^{2}$ irradiance, which is in the irradiance range of Atlas Suntest CPS/CPS+ in the ROS assay (10). We irradiated at up to $18 \mathrm{~J} / \mathrm{cm}^{2}$ at intervals of $3 \mathrm{~J} / \mathrm{cm}^{2}$ and recorded the phototoxic information. The results produced at 9 or more $\mathrm{J} / \mathrm{cm}^{2}$ were matched with their phototoxic potential (Table 1). Also, values of positive and negative substances met the acceptance criteria $(17,18)$. Considering the results obtained with the irradiation times, we selected the UVA dose of $9 \mathrm{~J} / \mathrm{cm}^{2}$ for the main study.

Results of ROS assay using UVA simulator. Using the selected UVA dose, we identified the performance of the ROS assay with 60 test substances including 50 phototoxins and 10 non-phototoxins (Table 2). Firstly, we measured an MEC for all the test substances if they were photoreactive. Four substances, ibuprofen, erythromycin, penicillin $G$ and phenytoin, had an MEC of less than 1,000. Next, we tested their solubility and identified precipitation, coloration or any other interference at $200 \mu \mathrm{M}$ in the reaction mixture. Amiodarone, demeclocycline, fenofibrate, piroxi- cam and rosiglitazone showed precipitation in the reaction mixture for SO and/or SA and an appropriate concentration was further explored for them. Except for amiodarone, the substances with the solubility issues were dissolvable at least at $20 \mu \mathrm{M}$. As such, the evaluable test substances were determined be 59 of the original 60 . The test results indicated that the UVA ROS assay correctly classified 42 of 49 phototoxins and 10 of 10 non-phototoxins. Amoxapine, atorvastatin, flutamide, griseofulvin, hydrochlorothiazide, nifedipine and nitrendipine were falsely judged as being non-phototoxins. The predictive capacity showed an $85.7 \%$ sensitivity, $100.0 \%$ specificity and $88.1 \%$ accuracy (Table 3 ).

\section{DISCUSSION}

To use a UVA simulator instead of validated solar simulators, we established the irradiation condition of the ROS assay with UVA. We chose a UVA irradiance of $2.0 \mathrm{~mW} /$ $\mathrm{cm}^{2}$, which has been used in Atlas Suntest CPS series and has shown the lowest variation in a previous study (6). We found an appropriate UVA intensity that was compatible with phototoxic information of reference chemicals (Table 1). Also, the selected intensity sufficiently generated ROS and in the range of $5 \sim 20 \mathrm{~J} / \mathrm{cm}^{2}$, which is widely used in in vitro and in vivo phototoxic assays (1).

Solubility evaluation of test substance solutions proceeded right before the assay, in order to prevent interference, such as precipitation and coloration that might affect

Table 1. Selection of UVA irradiation conditions using reference chemicals

\begin{tabular}{|c|c|c|c|c|c|c|c|c|c|c|c|c|c|}
\hline \multirow{2}{*}{ No. } & \multirow{2}{*}{ Substance name } & \multirow{2}{*}{ CAS no. } & \multicolumn{3}{|c|}{ Phototoxic information* } & \multicolumn{2}{|c|}{ "Concentration $(\mu \mathrm{M})$} & \multicolumn{6}{|c|}{ ROS assay $\left(\mathrm{J} / \mathrm{cm}^{2}\right)^{* *}$} \\
\hline & & & $3 \mathrm{~T} 3 \mathrm{NRU}$ & Animal & Human & $\mathrm{SO}$ & $\mathrm{SA}$ & 3 & 6 & 9 & 12 & 15 & 18 \\
\hline \multicolumn{14}{|c|}{ Positive/negative controls } \\
\hline 1 & Quinine $\mathrm{HCl}(\mathrm{PC})$ & $6119-47-7$ & $\mathrm{P}$ & $\mathrm{P}$ & $\mathrm{P}$ & 200 & 200 & + & + & + & + & + & + \\
\hline 2 & Sulisobenzone (NC) & $4065-45-6$ & $\mathrm{~N}$ & & $\mathrm{~N}$ & 200 & 200 & - & - & - & - & - & - \\
\hline \multicolumn{14}{|c|}{ Reference chemicals } \\
\hline 3 & 4-Aminobenzoic acid & $150-13-0$ & $\mathrm{~N}$ & $\mathrm{~N}$ & & 200 & 200 & - & - & - & - & - & - \\
\hline 4 & 8-Methoxy psoralen & $298-81-7$ & $\mathrm{P}$ & $\mathrm{P}$ & $\mathrm{P}$ & 200 & 200 & - & - & + & + & + & + \\
\hline 5 & Acridine & $260-94-6$ & $\mathrm{P}$ & $\mathrm{P}$ & $\mathrm{P}$ & 200 & 200 & + & + & + & + & + & + \\
\hline 6 & Benzocaine & $94-09-7$ & $\mathrm{~N}$ & & & 200 & 200 & - & - & - & - & - & - \\
\hline 7 & Chlorpromazine & $69-09-0$ & $\mathrm{P}$ & $\mathrm{P}$ & $\mathrm{P}$ & 200 & 200 & - & + & + & + & + & + \\
\hline 8 & Diclofenac & $15307-79-6$ & & & $\mathrm{P}$ & 200 & 200 & + & + & + & + & + & + \\
\hline 9 & Doxycycline & $10592-13-9$ & $\mathrm{P}$ & $\mathrm{P}$ & $\mathrm{P}$ & 200 & 200 & + & + & + & + & + & + \\
\hline 10 & Erythromycin & $114-07-8$ & $\mathrm{~N}$ & & & 200 & 200 & - & - & - & - & - & - \\
\hline 11 & Fenofibrate & $49562-28-9$ & $\mathrm{P}$ & & $\mathrm{P}$ & 20 & 20 & - & + & + & + & + & + \\
\hline 12 & Furosemide & $54-31-9$ & $\mathrm{P} / \mathrm{N}$ & & $\mathrm{P}$ & 200 & 200 & - & + & + & + & + & + \\
\hline 13 & L-Histidine & $71-00-1$ & $\mathrm{P}$ & & & 200 & 200 & - & - & - & - & - & - \\
\hline 14 & Ketoprofen & $22071-15-4$ & $\mathrm{P}$ & $\mathrm{N}$ & $\mathrm{P}$ & 200 & 200 & + & + & + & + & + & + \\
\hline 15 & Nalidixic acid & $389-08-2$ & $\mathrm{P}$ & $\mathrm{P}$ & $\mathrm{P}$ & 200 & 200 & + & + & + & + & + & + \\
\hline 16 & Norfloxacin & $70458-96-7$ & $\mathrm{P}$ & $\mathrm{P}$ & $\mathrm{P}$ & 200 & 200 & + & + & + & + & + & + \\
\hline 17 & Omeprazole & $73590-58-6$ & & & $\mathrm{P}$ & 200 & 200 & - & + & + & + & + & + \\
\hline 18 & Promethazine $\mathrm{HCl}$ & $58-33-3$ & $\mathrm{P}$ & & $\mathrm{P}$ & 200 & 200 & + & + & + & + & + & + \\
\hline
\end{tabular}

*Phototoxic information was from JaCVAM (17) and Onoue et al. (11); P, phototoxic; N, non-phototoxic. ${ }^{* *}+$, Positive result; - , Negative result. 
Table 2. Results of the UVA ROS assay

\begin{tabular}{|c|c|c|c|c|c|c|c|c|c|c|}
\hline \multirow{2}{*}{ No. } & \multirow{2}{*}{ Substance name } & \multirow{2}{*}{ CAS no. } & \multicolumn{2}{|c|}{ UV absorption* } & \multicolumn{2}{|c|}{$\begin{array}{c}\text { Concentration } \\
(\mu \mathrm{M})\end{array}$} & \multicolumn{3}{|c|}{ UVA ROS assay** } & \multirow{2}{*}{ - Phototoxic information } \\
\hline & & & $\begin{array}{l}\lambda_{\max } \\
(\mathrm{nm})\end{array}$ & $\begin{array}{c}\text { MEC } \\
\left(\mathrm{M}^{-1} \mathrm{~cm}^{-1}\right)\end{array}$ & SO & SA & SO & SA & Result & \\
\hline \multicolumn{11}{|c|}{ Positive/negative controls } \\
\hline 1 & Quinine $\mathrm{HCl}(\mathrm{PC})$ & $6119-47-7$ & 331 & 5250 & 200 & 200 & $279.6 \pm 24.5$ & $190.3 \pm 31.3$ & + & $(11),(17)$ \\
\hline 2 & Sulisobenzone (NC) & $4065-45-6$ & (290) & 9200 & 200 & 200 & $0.6 \pm 4.9$ & N.D. & - & (11) \\
\hline \multicolumn{11}{|c|}{ Phototoxic substances } \\
\hline 3 & 6-Methylcoumarin & $92-48-8$ & (290) & 8750 & 200 & 200 & $39.4 \pm 1.8$ & $53.7 \pm 4.5$ & + & $(11),(17)$ \\
\hline 4 & 8-Methoxy psoralen & $298-81-7$ & 300 & 12250 & 200 & 200 & $27.4 \pm 7.3$ & $18.6 \pm 3.5$ & + & $(11),(17)$ \\
\hline 5 & Acridine & $260-94-6$ & 355 & 9250 & 200 & 200 & $169.1 \pm 10.5$ & $95.1 \pm 4.0$ & + & $(11),(17)$ \\
\hline 6 & Amiodarone & $19774-82-4$ & $358 / 371$ & 10150 & 20 & 20 & N.A.(P) & N.A.(P) & $\mathrm{X}$ & $(11),(17)$ \\
\hline 7 & Amlodipine & $111470-99-6$ & 365 & 20900 & 200 & 200 & $9.9 \pm 12.2$ & $67.9 \pm 34.0$ & + & (18) \\
\hline 8 & Amoxapine & $14028-44-5$ & 298 & 9000 & 200 & 200 & N.D. & $14.2 \pm 10.3$ & - & (6) \\
\hline 9 & Atorvastatin & $134523-00-5$ & $(290)$ & 9200 & 200 & 200 & $13.1 \pm 6.9$ & $10.6 \pm 7.3$ & - & (18) \\
\hline 10 & Bezafibrate & $41859-67-0$ & (290) & 345 & 200 & 200 & $3.6 \pm 3.4$ & $24.8 \pm 3.9$ & + & (18) \\
\hline 11 & Bithionol & $97-18-7$ & 322 & 7750 & 200 & 200 & $80.7 \pm 7.2$ & $21.1 \pm 7.5$ & + & (11) \\
\hline 12 & Chlorothiazide & $58-94-6$ & 293 & 11950 & 200 & 200 & $3.6 \pm 1.2$ & $38.6 \pm 15.3$ & + & (6) \\
\hline 13 & Chlorpromazine $\mathrm{HCl}$ & $69-09-0$ & 293 & 4600 & 200 & 200 & N.D. & $55.0 \pm 17.6$ & + & (11), (17) \\
\hline 14 & Ciprofloxacin & $85721-33-1$ & 322 & 15300 & 200 & 200 & $198.3 \pm 54.0$ & $86.4 \pm 12.2$ & + & (15) \\
\hline 15 & Demeclocyline & $64-73-3$ & 375 & 15700 & 200 & 50 & $143.7 \pm 12.8$ & $46.1 \pm 2.0$ & + & (12) \\
\hline 16 & Diclofenac & $15307-79-6$ & $(290)$ & 7850 & 200 & 200 & $149.5 \pm 10.3$ & $150.8 \pm 32.6$ & + & (6) \\
\hline 17 & Doxycycline & $10592-13-9$ & 348 & 11650 & 200 & 200 & $67.2 \pm 9.1$ & $80.6 \pm 4.0$ & + & $(11),(17)$ \\
\hline 18 & Enoxacin & $74011-58-8$ & 334 & 13500 & 200 & 200 & $239.5 \pm 5.1$ & $357.6 \pm 2.3$ & + & (18) \\
\hline 19 & Fenofibrate & $49562-28-9$ & 294 & 11300 & 20 & 20 & $67.4 \pm 15.8$ & N.D. & + & (11), (17) \\
\hline 20 & Flutamide & $13311-84-7$ & 291 & 7800 & 200 & 200 & $12.7 \pm 4.1$ & $7.3 \pm 2.6$ & - & (14) \\
\hline 21 & Fluvastatin & $93957-55-2$ & 303 & 11050 & 200 & 200 & $190.4 \pm 3.4$ & $155.6 \pm 12.6$ & + & (18) \\
\hline 22 & Furosemide & $54-31-9$ & $(290)$ & 2850 & 200 & 200 & $74.3 \pm 21.2$ & $17.7 \pm 8.6$ & + & (11) \\
\hline 23 & Gliclazide & $21187-98-4$ & - & - & 200 & 200 & $4.3 \pm 10.2$ & $91.7 \pm 12.2$ & + & (18) \\
\hline 24 & Griseofulvin & $126-07-8$ & 295 & 24200 & 200 & 200 & $4.4 \pm 2.8$ & $10.6 \pm 2.9$ & - & (18) \\
\hline 25 & Hydrochlorothiazide & $58-93-5$ & 318 & 3350 & 200 & 200 & $1.9 \pm 3.3$ & N.D. & - & $(18),(19)$ \\
\hline 26 & Ibuprofen & $15687-27-1$ & 294 & 60 & 200 & 200 & $1.8 \pm 2.3$ & $62.7 \pm 10.7$ & + & (6) \\
\hline 27 & Ketoprofen & $22071-15-4$ & $(290)$ & 6450 & 200 & 200 & $123.5 \pm 12.8$ & $76.4 \pm 6.9$ & + & $(11),(17)$ \\
\hline 28 & Levofloxacin & 138199-71-0 & $(290)$ & 27150 & 200 & 200 & $107.3 \pm 28.6$ & $367.3 \pm 14.2$ & + & (18) \\
\hline 29 & Lomefloxacin & $98079-52-8$ & 326 & 13350 & 200 & 200 & $693.9 \pm 22.1$ & $64.5 \pm 1.5$ & + & (13) \\
\hline 30 & Losartan & $124750-99-8$ & (290) & 925 & 200 & 200 & N.D. & $50.3 \pm 3.2$ & + & (18) \\
\hline 31 & Lovastatin & $75330-75-5$ & $325 / 333$ & 1950 & 200 & 200 & $27.0 \pm 8.9$ & N.D. & + & (18) \\
\hline 32 & Meloxicam & $71125-38-7$ & $(290)$ & 8350 & 200 & 200 & $9.2 \pm 1.9$ & $31.9 \pm 9.7$ & + & (18) \\
\hline 33 & Mequitazine & $29216-28-2$ & 303 & 5850 & 200 & 200 & $114.3 \pm 11.9$ & $15.4 \pm 2.2$ & + & (18) \\
\hline 34 & Methotrexate & $59-05-2$ & 303 & 26100 & 200 & 200 & N.D. & $195.1 \pm 20.6$ & + & Package insert \\
\hline 35 & Nalidixic acid & $389-08-2$ & 335 & 12100 & 200 & 200 & $73.2 \pm 6.4$ & $307.0 \pm 16.8$ & + & $(11),(17)$ \\
\hline 36 & Naproxen & $22204-53-1$ & 293 & 3550 & 200 & 200 & $39.6 \pm 3.2$ & $77.9 \pm 8.2$ & + & (18) \\
\hline 37 & Nifedipine & $21829-25-4$ & 342 & 5850 & 200 & 200 & $8.8 \pm 3.2$ & N.D. & - & (6) \\
\hline 38 & Nitrendifine & $39562-70-4$ & 357 & 5000 & 200 & 200 & N.D. & $11.6 \pm 1.5$ & - & (6) \\
\hline 39 & Nitrofurantoin & $67-20-9$ & 381 & 20800 & 200 & 200 & $62.4 \pm 6.6$ & N.D. & + & (6) \\
\hline 40 & Norfloxacin & 70458-96-7 & 323 & 14450 & 200 & 200 & $167.3 \pm 24.1$ & $82.3 \pm 34.6$ & + & $(11),(17)$ \\
\hline 41 & Ofloxacin & 82419-36-1 & (290) & 28250 & 200 & 200 & $66.9 \pm 6.4$ & $349.6 \pm 11.6$ & + & (11), (17) \\
\hline 42 & Omeprazole & $73590-58-6$ & 299 & 14400 & 200 & 200 & N.D. & $92.0 \pm 6.3$ & + & (6) \\
\hline 43 & Oxytetracycline $\mathrm{HCl}$ & $2058-46-0$ & 358 & 16100 & 200 & 200 & $88.4 \pm 25.0$ & $66.8 \pm 9.4$ & + & (6) \\
\hline 44 & Perphenazine & $58-39-9$ & 309 & 3600 & 200 & 200 & N.D. & $47.8 \pm 9.5$ & + & (18) \\
\hline 45 & Piroxicam & $36322-90-4$ & 355 & 17900 & 200 & 50 & $99.9 \pm 5.8$ & $37.2 \pm 28.0$ & + & (11), (17) \\
\hline 46 & Pitavastatin & $147526-32-7$ & 291 & 10900 & 200 & 200 & N.A.(P) & $47.9 \pm 19.5$ & + & (18) \\
\hline 47 & Promethazine $\mathrm{HCl}$ & $58-33-3$ & 300 & 3500 & 200 & 200 & $59.5 \pm 4.0$ & $6.4 \pm 4.5$ & + & $(11),(17)$ \\
\hline 48 & Quinidine & $56-54-2$ & 331 & 5200 & 200 & 200 & $154.6 \pm 14.9$ & $87.6 \pm 16.1$ & + & (19) \\
\hline 49 & Rosiglitazone & $122320-73-4$ & 311 & 4900 & 200 & 20 & $31.9 \pm 5.9$ & $10.1 \pm 1.5$ & + & $(11),(17)$ \\
\hline 50 & Tetracycline & $60-54-8$ & 363 & 15950 & 200 & 200 & $39.5 \pm 5.4$ & $49.0 \pm 3.3$ & + & (11), (17) \\
\hline
\end{tabular}


Table 2. Continued

\begin{tabular}{|c|c|c|c|c|c|c|c|c|c|c|}
\hline \multirow{2}{*}{ No. } & \multirow{2}{*}{ Substance name } & \multirow{2}{*}{ CAS no. } & \multicolumn{2}{|c|}{ UV absorption* } & \multicolumn{2}{|c|}{$\begin{array}{c}\text { Concentration } \\
(\mu \mathrm{M})\end{array}$} & \multicolumn{3}{|c|}{ UVA ROS assay** } & \multirow{2}{*}{ Phototoxic information } \\
\hline & & & $\begin{array}{l}\lambda_{\max } \\
(\mathrm{nm})\end{array}$ & $\begin{array}{c}\mathrm{MEC} \\
\left(\mathrm{M}^{-1} \mathrm{~cm}^{-1}\right)\end{array}$ & SO & SA & SO & SA & Result & \\
\hline 51 & Tiaprofenic acid & $33005-95-7$ & 316 & 15500 & 200 & 200 & $654.5 \pm 23.0$ & $201.4 \pm 15.4$ & + & (12) \\
\hline \multicolumn{11}{|c|}{ Non-phototoxic substances } \\
\hline 52 & 4-Aminobenzoic acid & $150-13-0$ & (290) & 7300 & 200 & 200 & $-0.2 \pm 0.8$ & $-7.2 \pm 0.5$ & - & $(11),(17)$ \\
\hline 53 & Aspirin & $50-78-2$ & (290) & 2050 & 200 & 200 & $1.5 \pm 2.8$ & N.D. & - & $(11),(17)$ \\
\hline 54 & Benzocaine & $94-09-7$ & (290) & 16850 & 200 & 200 & N.D. & N.D. & - & $(11),(17)$ \\
\hline 55 & Dapsone & $80-08-0$ & 294 & 26250 & 200 & 200 & $10.7 \pm 2.3$ & N.D. & - & (19) \\
\hline 56 & Erythromycin & $114-07-8$ & - & - & 200 & 200 & N.D. & $15.1 \pm 0.4$ & - & (11), (17) \\
\hline 57 & L-Histidine & $71-00-1$ & 291 & 3000 & 200 & 200 & $0.7 \pm 0.6$ & $6.3 \pm 0.6$ & - & (11), (17) \\
\hline 58 & Octyl salicylate & $118-60-5$ & (290) & 12500 & 20 & 20 & $3.5 \pm 8.0$ & $4.6 \pm 3.8$ & - & (11), (17) \\
\hline 59 & Penicillin G & $113-98-4$ & - & - & 200 & 200 & $0.2 \pm 0.3$ & $9.8 \pm 0.7$ & - & (11), (17) \\
\hline 60 & Phenytoin & $57-41-0$ & 295 & 900 & 200 & 200 & N.D. & $15.4 \pm 0.9$ & - & (11), (17) \\
\hline
\end{tabular}

*When the maximum wavelengths were under $290 \mathrm{~nm}$, these are marked $290 \mathrm{~nm}$ with parentheses.

**SO: Singlet oxygen, SA: Superoxide anion, N.A. (P): Not available due to precipitation, N.D.: Not detected because SA or SO value was below zero.

the test results. To overcome a solubility problem, the ROS assay was modified to use the micelle system using Tween 20 (18). Thus, low solubility substances could be evaluated for their phototoxic potential by adapting the micellar system to the UVA ROS assay.

The study results showed that the 7 phototoxic substances, amoxapine, atorvastatin, flutamide, griseofulvin, hydrochlorothiazide, nifedipine and nitrendipine, were classified as non-phototoxins (Table 2). These substances showed a UVA absorption and MEC of over 1,000 but did not generate ROS, either singlet oxygen or superoxide anion species. Moreover, irradiation of UVA at up to $18 \mathrm{~J} / \mathrm{cm}^{2}$ did not generate ROS (data not shown). However, these substances were correctly classified in previous studies, which used a solar simulator $(6,18)$. Different results between a UVA simulator and a solar simulator could be related with UVB wavelength. UVB may be an essential factor to generate ROS of these chemicals, even they absorbed UVA wavelength. Therefore, misclassified chemicals may not generate ROS. On the other hand, the final concentration of a test chemical, $200 \mu \mathrm{M}$, could be limited to generate ROS in the UVA ROS assay system. If using more higher concentration than the final concentration, these chemicals would be generated ROS and met the criteria of photoreactivity. L-Histidine, penicillin $G$ and phenytoin that were false positive substances in the ROS assay were correctly classified as nonphototoxins (Table 2) $(6,9,11)$. Surprisingly, bezafibrate, gliclazide, ibuprofen and losartan generated superoxide anion and were thus classified as phototoxins even though they had low MEC values in the UV/VIS range (290 700 $\mathrm{nm})$. These results were consistent with those of the previous study, and MEC values cannot be always used to evaluate-phototoxic potential of chemicals (6). We conducted the UVA ROS assay with 60 test substances to identify their
Table 3. Comparison of predictive capacity of the UVA ROS assay with the standard ROS assay using two solar simulators

\begin{tabular}{lcccc}
\hline \hline & \multicolumn{2}{c}{ Standard ROS assay* } & & \multirow{2}{*}{$\begin{array}{c}\text { UVA ROS } \\
\text { assay }\end{array}$} \\
\cline { 2 - 3 } \cline { 5 - 5 } & $\begin{array}{c}\text { Suntest } \\
\text { CPS series }\end{array}$ & SXL-2500V2 & Biospectra \\
\hline Sensitivity (\%) & 100.0 & 100.0 & 85.7 \\
Specificity (\%) & 61.6 & 55.9 & & 100.0 \\
Accuracy (\%) & 86.8 & 88.7 & 88.1 \\
\hline
\end{tabular}

*Performance capacity was from Onoue et al. (11) and sensitivity, specificity and accuracy of each solar simulator in the ROS assay indicate the average of each participated lab results.

phototoxic potential. The results showed that this assay could adequately evaluate phototoxicity of the test substances analyzed. In addition, the UVA ROS assay has higher specificity and lower sensitivity than the ROS assay, and the performance of the UVA ROS assay is comparable with that of the ROS assay (Table 3). Our findings suggest that the UVA ROS assay could be used as a method for phototoxicity evaluation of pharmaceutical substances.

\section{ACKNOWLEDGMENTS}

This research was supported by a grant (15181MFDS458) from the Ministry of Food and Drug Safety of Korea in 2015.

\section{REFERENCES}

1. ICH (2013) Photosafety evaluation of pharmaceuticals S10, Step 4, ICH.

2. Schieber, M. and Chandel, N.S. (2014) ROS function in redox 
signaling and oxidative stress. Curr. Biol., 24, R453-R462.

3. Kim, K., Park, H. and Lim, K. (2015) Phototoxicity: Its mechanism and animal alternative test methods. Toxicol. Res., 31, 97-104.

4. Epstein, J.H. (1983) Phototoxicity and photoallergy in man. $J$. Am. Acad. Dermatol., 8, 141-147.

5. Gould, J.W., Mercurio, M.G. and Elmets, G.A. (1995) Cutaneous photosensitivity diseases induced by exogenous agents. $J$. Am. Acad. Dermatol., 33, 551-573.

6. Onoue, S., Igarashi, N., Yamada, S. and Yoshiko, T. (2008) High-throughput reactive oxygen species (ROS) assay: an enabling technology for screening the phototoxic potential of pharmaceutical substances. J. Pharm. Biomed. Anal., 46, 187193.

7. EMA (2002) Note for Guidance on Photosafety Testing, EMA, London.

8. CDER/FDA (2003) Guidance for Industry Photosafety Testing, CDER/FDA

9. Onoue, S., Hosoi, K., Wakuri, S., Iwase, Y., Yamamoto, T., Matsuoka, N., Nakamura, K., Toda, T., Takagi, H., Osaki, N., Matsumoto, Y., Kawakami, S., Seto, Y., Kato, M., Yamada, S., Ohno, Y. and Kojima, H. (2013) Establishment and intra-/ inter-laboratory validation of a standard protocol of reactive oxygen species assay for chemical photosafety evaluation. $J$. Appl. Toxicol., 33, 1241-1250.

10. JaCVAM (2014) Reactive oxygen species (ROS) assay to examine photoreactivity of chemicals. Version 3.2 [2014 Nov 28].

11. Onoue, S., Hosoi, K., Toda, T., Takagi, H., Osaki, N., Matsumoto, Y., Kawakami, S., Wakuri, S., Iwase, Y., Yamamoto, T., Nakamura, K., Ohno, Y. and Kojima, H. (2014) Intra-/interlaboratory validation study on reactive oxygen species assay for chemical photosafety evaluation using two different solar simulators. Toxicol. In Vitro, 28, 515-523.

12. Spielmann, H., Balls, M., Dupuis, J., Pape, W.J., Pechovitch, G., de Silva, O., Holzhütter, H.G., Clothier, R., Desolle, P.,
Gerberick, F., Liebsch, M., Lovell, W.W., Maurer, T, Pfannenbecker, U., Potthast, J.M., Csato, M., Sladowski, D., Steiling, W. and Brantom, P. (1998) The international EU/COLIPA in vitro phototoxicity validation study: results of phase II (blind trial). Part 1: the $3 \mathrm{~T} 3 \mathrm{NRU}$ phototoxicity test. Toxicol. In Vitro, 12, 305-327.

13. Lelièvre, D., Justine, P., Christiaens, F., Bonaventure, N., Coutet, J., Marrot, L. and Cotovio, J. (2007) The episkin phototoxicity assay (EPA): Development of an in vitro tiered strategy using 17 reference chemicals to predict phototoxic potency. Toxicol. In Vitro, 21, 977-995.

14. Kleinmann, M.H., Smith, M.D., Kurali, E., Kleinpeter, S., Jiang, K., Zhang, Y., Kennedy-Gabb, S.A., Lynch, A.M. and Geddes, C.D. (2010) An evaluation of chemical photoreactivity and the relationship to phototoxicity. Regul. Toxicol. Pharmacol., 58, 224-232.

15. Lynch, A.M., Smith, M.D., Lane, A.S., Robinson, S.A., Kleinman, M.H., Kennedy-Gabb, S., Wilcox, P. and Rees, R.W. (2010) An evaluation of chemical photoreactivity and the relationship to photogenotoxicity. Regul. Toxicol. Pharmacol., 58, 219-223.

16. Haranosono, Y., Kurata, M. and Sakaki, H. (2014) Establishment of an in silico phototoxicity prediction method by combining descriptors related to photo-absorption and photoreaction. J. Toxicol. Sci., 39, 655-664.

17. JaCVAM (2013) Validation report for the international validation study on ROS (Reactive Oxygen Species) assay as a test evaluating phototoxic potential of chemicals (Atlas Suntest version) [2013 Nov 20].

18. Seto, Y., Kato, M., Yamada, S. and Onoue, S. (2013) Development of micellar reactive oxygen species assay for photosafety evaluation of poorly water-soluble chemicals. Toxicol. In Vitro, 27, 1838-1846.

19. Lugović, L., Situm, M., Ozanić-Bulić, S. and SjerobabskiMasnec, I. (2007) Phototoxic and photoallergic skin reactions. Coll. Antropol., 31 Suppl 1, 63-67. 